\title{
Identification of the Thrombin Receptor on Human Platelets by Chemical Crosslinking
}

\author{
Junki Takamatsu, McDonald K. Horne III, and Harvey R. Gralnick
}

Hematology Service, Clinical Pathology Department, Clinical Center, National Institutes of Health, Building 10, Room 2C390, Bethesda, Maryland 20892

\section{Abstract}

To identify the molecular site of thrombin binding to the platelet membrane, we covalently linked ${ }^{125}$ I-thrombin to platelets by using the bifunctional chemical cross-linking agents disuccinimidyl suberate and dithiobis(succinimidyl propionate). The proteins cross-linked to ${ }^{125} \mathrm{I}$-thrombin by this method were analyzed by sodium dodecyl sulfate-polyacrylamide gel electrophoresis and followed by autoradiography. Two radiolabeled thrombin complexes were identified, a major species of $\dot{M}_{\mathbf{r}} \sim 200,000$ and a minor one of $M_{r} \sim 400,000$. Hirudin prevented the formation of both complexes. The radioactivity of the $\sim 200,000-M_{\mathrm{r}}$ complex was always 7-10-fold greater than the radioactivity of the $\sim \mathbf{4 0 0 , 0 0 0}-M_{\mathrm{r}}$ complex regardless of the thrombin concentration to which the platelets were exposed (0.1-29 nM). Although ${ }^{125} \mathrm{I}$ thrombin complexes generated with thrombasthenic platelets (lacking glycoprotein IIb/IIIa) were indistinguishable from normal, no complexes appeared when Bernard-Soulier platelets (lacking glycoprotein Ib [GPIb]) were used. Complex formation was blocked by rabbit antiglycocalicin antiserum, but not by the monoclonal antibody 6D1, which is directed against the site on GPIb where von Willebrand factor (vWf) binds in the presence of ristocetin. Although cross-linking studies suggested that $\mathrm{vWf}$ might partially inhibit thrombin binding to platelets, this was not confirmed by equilibrium binding studies in the presence of vWf and ristocetin. The data suggest, therefore, that at all thrombin concentrations binding occurs at the same membrane site, despite evidence from equilibrium studies for high and low affinity classes of receptors, and that the $\sim 400,000-M_{\mathrm{r}}$ complex is simply a dimer of the $\sim 200,000-M_{\mathrm{r}}$ species. We conclude that the membrane site to which thrombin binds is the glycocalicin portion of platelet GPIb at a site remote from the point of ristocetin-dependent $\mathrm{vWf}$ binding.

\section{Introduction}

Alpha thrombin is an important and potent activator of platelet function (1). Although the mechanisms of its action are not completely understood, thrombin appears to bind to specific sites on the platelet surface. Tollefsen et al. (2) defined two classes of binding sites by equilibrium binding studies. One class is

\footnotetext{
A portion of this work has been reported at the meeting of the American Society for Clinical Investigation, Washington, DC, May, 1985.

Address correspondence to Dr. Gralnick. Dr. Takamatsu's present address is The First Department of Internal Medicine, Nagoya University School of Medicine, Showaku Nagoya 466, Japan.

Received for publication 24 June 1985 and in revised form 30 September 1985.
}

The Journal of Clinical Investigation, Inc.

Volume 77, February 1986, 362-368 characterized by a relatively low surface density ( $\sim 500$ sites/ cell) and by binding at thrombin concentrations corresponding to the threshold at which physiological responses occur $\left(K_{d} \sim 0.2\right.$ $\mathrm{nM})$. The other class is present in greater numbers $(\sim 50,000$ sites/cell) but has a lower affinity for thrombin $\left(K_{\mathrm{d}} \sim 30 \mathrm{nM}\right)$ and uncertain physiologic significance.

Whether these classes of binding sites represent different membrane structures or negative cooperativity within a single structure has never been clarified, nor have any of the membrane structures involved been identified with certainty. Nevertheless, several reports have implicated the membrane glycoprotein $\mathrm{Ib}$ (GPIb) ${ }^{1}$ as the thrombin receptor. Purified GPIb and its derivative glycocalicin competitively inhibit thrombin binding to both classes of sites $(3,4)$. Yet, Fab fragments of anti-GPIb antisera are reported to have minimal effect on platelet aggregation induced by thrombin (5). Platelets from patients with BernardSoulier syndrome, which lack GPIb, bind decreased amounts of thrombin (6). However, these platelets are known to have other membrane abnormalities as well (7).

We have attempted to identify the platelet receptor for thrombin by chemically cross-linking ${ }^{125} \mathrm{I}$-thrombin to intact platelets with bifunctional cross-linking agents and analyzing the radioactive complexes with sodium dodecyl sulfate-polyacrylamide gel electrophoresis (SDS-PAGE). We have used normal platelets, Bernard-Soulier platelets, and platelets from patients with Glanzmann's thrombasthenia, which lack the membrane glycoprotein IIb/IIIa (GPIIb/IIIa) complex (8). In addition, we have studied thrombin binding to normal platelets in the presence of several antibodies specific for certain membrane components and in the presence of von Willebrand factor (vWf) and ristocetin. In some instances, the cross-linking studies have been supplemented with binding studies under equilibrium conditions. We have obtained evidence that the platelet has only one binding site for thrombin, and that this is located on GPIb at a point remote from where $\mathrm{vWf}$ binds in the presence of ristocetin.

\section{Methods}

Human blood was obtained from healthy donors, patients with Glanzmann's thrombasthenia, and patients with the Bernard-Soulier syndrome. All subjects were informed about the scope of the study. Venipuncture was performed using a 19-gauge needle. Blood was collected into 0.1 volumes of $0.13 \mathrm{M}$ sodium citrate, $10 \mathrm{mM} \mathrm{Na}{ }_{2}$ EDTA, in polypropylene tubes. Platelet-rich plasma (PRP) was prepared from normal and throm-

1. Abbreviations used in this paper: DFP, diisopropylfluorophosphate; DSP, dithiobis(succinimidyl propionate); DSS, disuccinimidyl suberate; DTT, dithiothreitol; GPIb, glycoprotein Ib; GPIIb/IIIa, glycoprotein IIb/ IIIa; NEM, $N^{\prime}$-ethylmaleimide; PRP, platelet-rich plasma; SDS-PAGE, sodium dodecyl sulfate-polyacrylamide gel electrophoresis; vWf, von Willebrand factor. 
basthenic blood by centrifugation at $500 \mathrm{~g}$ for $10 \mathrm{~min}$ at $24^{\circ} \mathrm{C}$. Platelets were isolated from this PRP on an arabino-galactan gradient as previously described (9). Bernard-Soulier PRP was produced by allowing the whole blood to sediment at room temperture for $3 \mathrm{~h}$. Platelets were collected from the Bernard-Soulier PRP by washing away the plasma with salinephosphate-EDTA buffer $(0.15 \mathrm{M} \mathrm{NaCl}, 10 \mathrm{mM}$ sodium phosphate, and $10 \mathrm{mM} \mathrm{Na}{ }_{2}$ EDTA, pH 7.4) containing $1 \%$ bovine serum albumin (BSA). All platelets were suspended in this buffer, and in some experiments 6 $\mathrm{mM} N^{\prime}$-ethylmaleimide (NEM) and $1 \mathrm{mM}$ leupeptin were included.

Highly purified alpha thrombin, $\sim 3,000 \mathrm{U} / \mathrm{mg}$, was provided by $\mathrm{Dr}$. John Fenton, New York State Dept. of Health, Albany, NY. The thrombin was iodinated $\left(\mathrm{Na}^{125} \mathrm{I}\right)$ using agarose-bound lactoperoxidase as previously described (10). Iodination did not alter the fibrinogen clotting activity of the thrombin (11). ${ }^{125}$ I-thrombin was treated with diisopropylfluorophosphate (DFP) by the method of Tollefson et al. (2).

Equilibrium binding studies. Isolated platelets were suspended in Tyrode's buffer $(0.14 \mathrm{M} \mathrm{NaCl}, 3 \mathrm{mM} \mathrm{KCl}, 12 \mathrm{mM} \mathrm{NaHCO}, 0.4 \mathrm{mM}$ $\mathrm{NaH}_{2} \mathrm{PO}_{4}, 2 \mathrm{mM} \mathrm{CaCl}$, and $1 \mathrm{mM} \mathrm{MgCl} 2, \mathrm{pH} \mathrm{7.35)}$ with 5\% BSA to give a final concentration of $4.8 \times 10^{8} / \mathrm{ml}$ normal platelets and $2.4 \times 10^{8} /$ $\mathrm{ml}$ Bernard-Soulier platelets. Binding experiments were performed at room temperature by mixing $0.2 \mathrm{ml}$ of the platelet suspensions with 0.2 $\mathrm{ml}$ of ${ }^{125} \mathrm{I}$-thrombin (final concentration, $0.004-8.0 \mathrm{U} / \mathrm{ml}$ ) in polyethylene tubes. The total radioactivity (cpm) of each sample was measured in an automatic gamma counter (Tracor Analytic, model 1185). The samples were incubated for $30 \mathrm{~min}$. We (unpublished data) and others (2) have previously shown that binding equilibrium is reached within $10-15 \mathrm{~min}$. After incubation the tubes were centrifuged at $2,000 \mathrm{~g}$ for $8 \mathrm{~min}$, and the supernatants aspirated without disturbing the platelet pellets. The radioactivity of the tubes was remeasured after aspiration to obtain bound ${ }^{125} \mathrm{I}$-thrombin. Unbound (supernatant) ${ }^{125} \mathrm{I}$-thrombin was calculated as total minus bound cpm. Nonspecifically bound thrombin was measured by including hirudin $20 \mathrm{U} / \mathrm{ml}$ in the thrombin-platelet mixtures. Radioactivity measurements were converted to units of thrombin concentration by determining the specific activity of the labeled thrombin $\left(3.3 \times 10^{5}\right.$ $\mathrm{cpm} / \mathrm{U})$.

Equilibrium binding of ${ }^{125} I$-thrombin in the presence of $v W f$ and ristocetin or antiglycocalicin antiserum. Platelets $\left(2 \times 10^{8} / \mathrm{ml}\right)$ were suspended in saline-phosphate-EDTA buffer containing $1 \%$ BSA, 2-100 $\mu \mathrm{g} / \mathrm{ml} \mathrm{vWf}$, and ristocetin $(0,1$, or $2 \mathrm{mg} / \mathrm{ml}) .0 .2 \mathrm{ml}$ of the platelet suspension was mixed with $0.2 \mathrm{ml}$ of $20 \mathrm{nM}{ }^{125} \mathrm{I}$-thrombin for $15 \mathrm{~min}$ before the cells were isolated by centrifugation. In other experiments, the platelet-thrombin mixtures contained $20 \%$ (vol/vol) rabbit antiglycocalicin antiserum obtained from Dr. N. O. Solum (12), University of Oslo, Norway, or an equivalent volume of rabbit preimmune serum with or without hirudin. The concentrations of bound and free thrombin were determined as described above.

Cross-linking protocol. Platelets $\left(10^{9} / \mathrm{ml}\right)$ were incubated for $15 \mathrm{~min}$ at room temperature with ${ }^{125} \mathrm{I}$-thrombin $(0.1-100 \mathrm{nM})$. In our initial studies, this incubation was in saline-phosphate-EDTA, but in other experiments the protease inhibitors leupeptin and NEM were also added as a precaution. However, the presence of NEM and leupeptin did not alter the results obtained with SDS-PAGE. In some experiments inhibitors of thrombin or other agents were added to the platelets before thrombin or a cross-linking agent was added. Hirudin $(20 \mathrm{U} / \mathrm{ml})$, purified human vWf, ristocetin, the murine monoclonal antibodies 6Dl and 10E5 (gifts from Dr. Barry Coller, State University of New York at Stony Brook, $\mathrm{NY}$ ), and the rabbit polyclonal antiserum against glycocalicin (from Dr. Solum) were tested. The vWf was purified as previously described (13). The monoclonal antibody $6 \mathrm{D} 1$ is directed against the site on GPIb which $\mathrm{vWf}$ binds in the presence of ristocetin (14). The antibody $10 \mathrm{E} 5$ reacts with the GPIIb/IIla complex where fibrinogen binds (15).

After incubation, the platelets were rinsed once with saline-phosphateEDTA and resuspended in the same buffer. The bifunctional cross-linking agents disuccinimidyl suberate (DSS) (16) or dithiobis(succinimidyl propionate) (DSP) (17) were freshly prepared. The formation of the radiolabeled cross-linked complexes was followed for $20 \mathrm{~s}$ to $60 \mathrm{~min}$ by analysis with SDS-PAGE and autoradiography. Although complexes appeared by $40 \mathrm{~s}$ and their radioactive intensity stabilized by $80 \mathrm{~s}$, the cross-linking reaction was typically allowed to proceed for $15 \mathrm{~min}$ at ice-bath temperature before quenching with 10 or more volumes of ice-cold $10 \mathrm{mM}$ Tris $\mathrm{HCl}, 1 \mathrm{mM}$ EDTA (pH 7.4 for DSS; $\mathrm{pH} 8.5$ for DSP). This mixture was centrifuged at $2,000 \mathrm{~g}$ for $30 \mathrm{~min}$ at $25^{\circ} \mathrm{C}$. The pellet was dissolved in $3.3 \% \mathrm{SDS}$ with heating at $100^{\circ} \mathrm{C}$ for $5-10 \mathrm{~min}$. The sample was then centrifuged at $20,000 \mathrm{~g}$ for $60 \mathrm{~min}$ at $25^{\circ} \mathrm{C}$. The supernatant was mixed with sample buffer $(0.0625 \mathrm{M}$ Tris $\mathrm{HCl}, 1 \% \mathrm{SDS}, \mathrm{pH}$ 6.8) for electrophoresis.

SDS gel electrophoresis and autoradiography. Samples were heated in sample buffer with or without reducing agent $(10 \mathrm{mM}$ dithiothreitol [DTT]) at $100^{\circ} \mathrm{C}$ for $5 \mathrm{~min}$ before loading onto a $1.5-\mathrm{mm}$ thick slab gel. The Laemmli system of electrophoresis buffers was used (18). The separating gels were composed of 5\% acrylamide, $10 \%$ acrylamide, or a composite of $0.5 \%$ agarose and $2.25 \%$ acrylamide. Stacking gels of $3 \%$ acrylamide were used with the $5 \%$ gels. After electrophoresis the gels were stained with Coomassie Blue, dried and exposed to X-Omat AR film (Eastman Kodak Co., Rochester, NY) at $-70^{\circ} \mathrm{C}$. On occasion gels were sliced at $2-\mathrm{mm}$ intervals, and the radioactivity of the individual slices was determined.

Reagents. DSS and DSP were purchased from Pierce Chemical Co. (Rockford, IL). Litex agarose was purchased from Accurate Chemical and Scientific Corp. (Denver, $\mathrm{CO}$ ), and acrylamide and bisacrylamide were purchased from Bio-Rad Laboratories (Richmond, CA). $\mathrm{Na}^{125} \mathrm{I}$ was from Amersham Corp. (Arlington Heights, IL). Ristocetin was purchased from Lundbeck (Copenhagen, Denmark). NEM was obtained from Aldrich Chemical Co. (Milwaukee, WI). Leupeptin, lactoperoxidase, DFP, and hirudin were from Sigma Chemical Co. (St. Louis, MO). All other chemicals used in this study were of reagent grade.

\section{Results}

Addition of the cross-linking agent DSP to preincubated mixtures of ${ }^{125} \mathrm{I}$-thrombin and platelets resulted in the appearance of three bands of radioactivity on 5\% SDS-PAGE (Fig. 1). Identical results were obtained when ${ }^{125}$ I-DFP-thrombin was substituted. A control study performed with ${ }^{125} \mathrm{I}$-thrombin and DSS but without platelets showed only an ${ }^{125} \mathrm{I}$ band corresponding to monomeric thrombin in 5\% gels. Another control that included ${ }^{125} \mathrm{I}$-thrombin

[DSP] (mM)

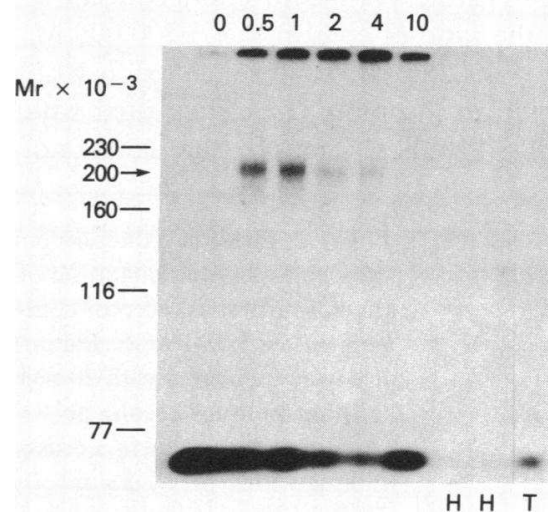

Figure 1. Autoradiograph of SDS-PAGE slab gel showing the effect of various concentrations of DSP $(0-10 \mathrm{mM})$ on ${ }^{125}$ I-thrombin-platelet cross-linking. The samples in the lanes marked $\mathrm{H}$ were cross-linked with $1 \mathrm{mM}$ DSP in the presence of hirudin $(10 \mathrm{U} / \mathrm{ml}, 20 \mathrm{U} / \mathrm{ml})$. The lane marked $\mathrm{T}$ shows ${ }^{125} \mathrm{I}$-thrombin electrophoresed without platelets or cross-linking agent. The migration distances of the molecular weight standards are indicated on the left side of the figure. The standard proteinsincluded reduced $\mathrm{vWf}\left(M_{\mathrm{r}} 230,000\right)$, intact $\operatorname{IgG}\left(M_{\mathrm{r}} 160,000\right)$, $\beta$-galactosidase $\left(M_{\mathrm{r}} 116,000\right)$, and transferrin $\left(M_{\mathrm{r}} 77,000\right)$. The arrow on the left denotes the cross-linked complex $\left(M_{\mathrm{r}} \sim 200,000\right)$. 
and platelets but no cross-linking agent revealed only an ${ }^{125} \mathrm{I}$ band that also co-migrated with free thrombin (not shown). These bands seen in the controls corresponded to the most rapidly migrating band of radioactivity in the cross-linked samples. Furthermore, when the cross-linked samples (formed with the thio-cleavable agent DSP) were treated with a reducing agent (DTT), the two bands of higher $M_{\mathrm{r}}$ disappeared, while the band at $M_{\mathrm{r}} \sim 38,000$ remained. This confirmed that the two bands of higher $M_{\mathrm{r}}$ were in fact due to covalent cross-linking by DSP, and that the band at $M_{\mathrm{r}} 38,000$ was not a cross-linked species (Fig. 2).

The same pattern of radioactive bands was present in unreduced samples cross-linked with the noncleavable agent DSS (Fig. 2). In contrast, under reducing conditions, the middle band with $M_{\mathrm{r}} \sim 200,000$ migrated slightly further to a position corresponding to $M_{\mathrm{r}} \sim 180,000$. With $10 \%$ SDS-PAGE, only two autoradiographic bands appeared, one at the origin $\left(M_{\mathrm{r}}\right.$ $>180,000)$ and one at $M_{\mathrm{r}} \sim 38,000$, co-migrating with free ${ }^{125} \mathrm{I}$ thrombin (data not shown).

The intensity of the unreduced middle band on 5\% SDSPAGE was maximal with $0.5 \mathrm{mM}$ and $1 \mathrm{mM}$ DSP (Fig. 1). At higher concentrations of DSP, less of the cross-linked material could be dissolved in SDS. When $10 \mathrm{mM}$ DSP was used, only $38 \%$ of the radiolabeled material remained in the supernatant of samples centrifuged at $20,000 \mathrm{~g}$ for $60 \mathrm{~min}$, whereas with 1 mM DSP, $90 \%$ of the radioactivity remained in the supernatant, and in the absence of DSP 94\% remained soluble. Therefore, 1 mM DSP was used in subsequent experiments.

With an initial thrombin concentration of $20 \mathrm{nM}$ and a platelet concentration of $10^{9} / \mathrm{ml}, \sim 2.5 \%$ of the total thrombin in an individual sample became bound to the platelets. With 1 mM DSP, $\sim 15 \%$ of this platelet-bound ${ }^{125}$ I-thrombin migrated with the $\sim 200,000-M_{\mathrm{r}}$ complex, as quantitated by measuring the radioactivity of 2-mm gel slices.

A third band of radioactivity remained at the top of $5 \%$ gels (Fig. 1). In more porous slab gels, however, this band diminished and a faint band appeared with $M_{\mathrm{r}} \sim 400,000$ (Fig. 3). On occasion, such slabs were cut into 2-mm slices and the radioactivity of the slices quantitated. Regardless of the thrombin concentration used $(0.1-20 \mathrm{nM})$, the ratio of $\mathrm{cpm}$ in the $\sim 200,000-M_{\mathrm{r}}$ band to the cpm in the $\sim 400,000-M_{\mathrm{r}}$ band remained 7-10:1 When platelets, unexposed to thrombin, were incubated with DSP and separated by SDS-PAGE, Coomassie Blue staining of

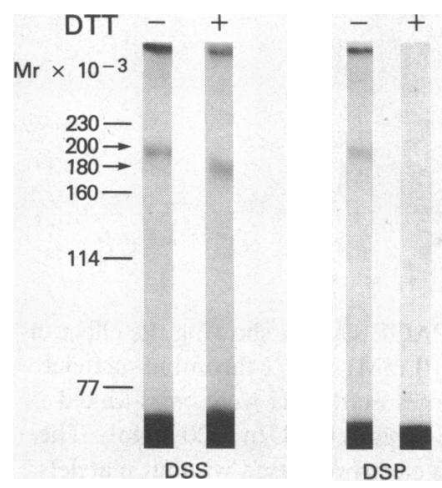

Figure 2. Effect of reduction on the electrophoretic migration of the ${ }^{125}$ I-thrombin receptor complex on 5\% SDS-PAGE. Platelets were incubated with $20 \mathrm{nM}$ ${ }^{125}$ I-thrombin for $15 \mathrm{~min}$ at room temperature before crosslinking with $1 \mathrm{mM}$ DSS or DSP. Lanes of samples reduced with $10 \mathrm{mM}$ DTT are marked + . Arrows show the $\sim 200,000$ $M_{\mathrm{r}}$ complex before reduction and the $\sim 180,000-M_{\mathrm{r}}$ species after reduction when the noncleavable agent DSS is used. In contrast, when DSP (thio-cleavable) is employed, the radiolabeled band at $M_{\mathrm{r}} \sim 200,000$ is absent in the presence of DTT (i.e., the ${ }^{125} \mathrm{I}$ thrombin is cleaved from the complex). Molecular weight standards were the same as in Fig. 1.

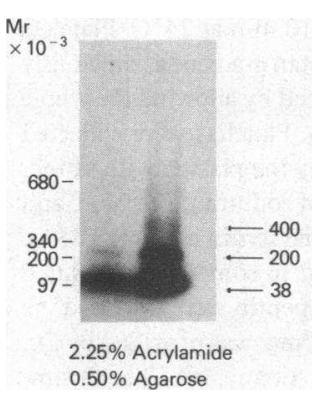

Figure 3. Autoradiograph of ${ }^{125} \mathrm{I}$-thrombin platelet complexes electrophoresed in a slab gel of $0.5 \%$ agarose and $2.25 \%$ acrylamide. Platelets were incubated with 5 $\mathrm{nM}$ (left lane) and $20 \mathrm{nM}$ (right lane) ${ }^{125} \mathrm{I}-$ thrombin. The migration distances of the molecular weight standards are indicated on the left side of the figure. The standard proteins included monomeric and dimeric fibrinogen $\left(M_{\mathrm{r}} 340,000\right.$ and 680,000$)$, myosin H-chain $\left(M_{\mathrm{r}} 200,000\right)$, and phophorylase $\mathrm{B}\left(M_{\mathrm{r}} 97,000\right)$. Three autoradiographic bands with $M_{\mathrm{r}} \sim 400,000, \sim 200,000$, and $\sim 38,000$ (dye front) are noted. Free ${ }^{125} \mathrm{I}$-thrombin co-migrates with the band at $M_{\mathrm{r}}$ $\sim 38,000$.

the gels revealed a protein pattern similar to that of non-crosslinked platelets, but with a large amount of material remaining at the origin (Fig. 4).

When hirudin was added to the thrombin-platelet mixtures, subsequent cross-linking with DSP produced no $M_{\mathrm{r}} 200,000^{125} \mathrm{I}$ thrombin complex. A faint band was present on 5\% SDS-PAGE, corresponding to free thrombin nonspecifically associated with the platelets, and a small amount of radioactivity remained at the top of the gel (Fig. 1, lane $H$ and Fig. 9, lane 3). Unlabeled thrombin competed with ${ }^{125}$ I-thrombin for binding to platelets, as shown in Fig. 5. At a molar ratio of labeled to unlabeled thrombin of $1: 1$, there was a slight diminution in the appearance of the $\sim 200,000-M_{\mathrm{r}}$ band, and at ratios of 1:100 and 1:500 the radioactive $\sim 200,000-M_{\mathrm{r}}$ band was not seen.

When platelets from a patient with the Bernard-Soulier syndrome (lacking GPIb) were substituted for normal platelets in the cross-linking studies, no radioactive bands appeared at $M_{\mathbf{r}}$ $\sim 200,000$ or $\sim 400,000$ in gels of $0.5 \%$ agarose and $2.25 \%$ acrylamide (Fig. 6). To confirm this apparent lack of thrombin binding to the Bernard-Soulier platelets, an equilibrium binding study was performed. A Scatchard plot of the data is shown in Fig. 7. For comparison, a parallel study with normal platelets is also presented. The only binding demonstrable to the BernardSoulier platelets is represented by a horizontal line (bound/free $=2.3 \pm 0.45 \mathrm{ml} / 10^{10}$ cells, mean $\pm \mathrm{SD}$ ), which approximates the asymptote approached by the hyperbolic plot of the data for the normal platelets. The intercept of this line also coincides with the constant bound/free ratio observed in the presence of hirudin $\left(2.6 \pm 0.40 \mathrm{ml} / 10^{10}\right.$ cells, mean $\left.\pm \mathrm{SD}\right)$ with free thrombin concentrations of $0.01-6 \mathrm{U} / \mathrm{ml}$. By these criteria, the thrombin associated with the Bernard-Soulier platelets represents only nonspecific (unsaturable) binding.

SDS-PAGE of the platelets from a patient with Glanzmann's

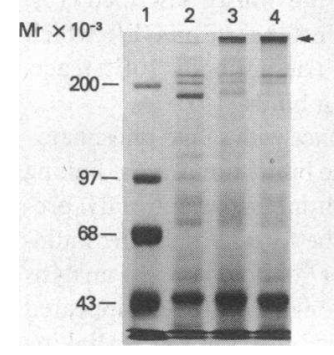

Figure 4. Coomassie Blue stain of $5 \%$ SDS-PAGE slab gel of control platelets (lane 2) and platelets treated with $1 \mathrm{mM}$ DSS (lane 3) or $1 \mathrm{mM}$ DSP (lane 4). Note the excessive amount of protein remaining at the top of the lanes containing the cross-linked samples. The molecular weight standards (lane 1 ) included myosin H-chain $\left(M_{\mathrm{r}} 200,000\right)$, phosphorylase B $\left(M_{\mathrm{r}} 97,000\right)$, bovine serum albumin $\left(M_{\mathrm{r}}\right.$ $68,000)$, ovalbumin $\left(M_{\mathrm{r}} 43,000\right)$, alpha chymotrypsin $\left(M_{\mathrm{r}} 25,700\right)$, and $\beta$-lactoglobulin $\left(M_{\mathrm{r}} 18,400\right)$. 


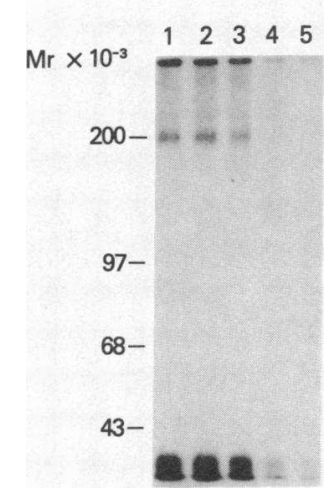

Figure 5. Effect of unlabeled thrombin on the formation of the $M_{\mathrm{r}} \sim 200,000$ complex of ${ }^{125} \mathrm{I}$-thrombin and platelet protein. ${ }^{125} \mathrm{I}$-thrombin $(20 \mathrm{mM})$ was mixed with native thrombin in a ratio of unlabeled to labeled of 1:1 (lane 2), 10:1 (lane 3), 500:1 (lane 4), or 1,000:1 (lane 5) before being added to the platelets and cross-linked with $1 \mathrm{mM}$ DSP. No unlabeled thrombin was added to the ${ }^{125} \mathrm{I}$-thrombin used in the sample in lane 1 . The ${ }^{125} \mathrm{I}$-thrombin was effectively displaced from the thrombin-platelet complexes by unlabeled thrombin.

thrombasthenia incubated with thrombin and cross-linking agents is shown in Fig. 8. Despite the lack of the GPIIb/IIIa complex in these platelets (8), the radioactive bands derived by thrombin cross-linking were indistinguishable from those seen with normal platelets.

In an attempt to identify the submolecular components of the membrane site(s) involved in thrombin binding, we studied the effect of two monoclonal and one polyclonal antibody against platelet glycoproteins. Neither the monoclonal antibody, 6D1, which is directed against the ristocetin-dependent $\mathrm{vWf}$ binding site on GPIb, nor the monoclonal antibody, 10E5, which is directed against the fibrinogen binding site on GPIIb/IIIa, altered the appearance of the crosslinked bands appearing on 5\% gels. However, the polyclonal antibody against glycocalicin completely inhibited the formation of the ${ }^{125}$ I-thrombin-platelet complexes (Fig. 9). Preimmune serum had no discernible effect. The inhibition by antiglycocalicin was confirmed by measuring the equilibrium binding of $20 \mathrm{nM}$ thrombin to platelets in the presence of the antibody and in the presence of preimmune serum with and without hirudin. Even though the concentration of antiserum was less in these experiments than in the crosslinking studies ( 20 vs. $50 \%$, vol/vol), $\sim 80 \%$ of the specific binding at equilibrium was inhibited by the antibody.

Incubating platelets with ${ }^{125} \mathrm{I}$-thrombin in the presence of vWf and ristocetin appeared to reduce the intensity of the $\sim 200,000-M_{\mathrm{r}}$ band by $\sim 20 \%$ (Fig. 10), whereas $\mathrm{vWf}$ alone had no apparent effect. However, equilibrium binding studies with $20 \mathrm{nM}$ thrombin in the presence of ristocetin $(1$ or $2 \mathrm{mg} / \mathrm{ml}$ ) and $v W f(2-100 \mu \mathrm{g} / \mathrm{ml})$ failed to demonstrate any inhibition (Fig. 11).

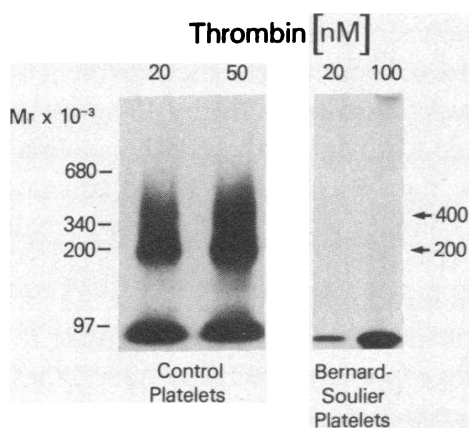

Figure 6. Analysis of the ${ }^{125}$ I-thrombin-platelet complexes of normal $(l e f t)$ and Bernard-Soulier (right) platelets in an SDS-gel of $0.5 \%$ agarose and $2.25 \%$ acrylamide. Normal platelets were incubated with 20 and $50 \mathrm{nM}^{125}$ I-thrombin, while the Bernard-Soulier patient's platelets were incubated with $20 \mathrm{nM}$ and 100 nM ${ }^{125}$ I-thrombin. Cross-

linking was performed with $1 \mathrm{mM}$ DSS. Molecular weight standards were the same as in Fig. 3. The arrows indicate radiolabeled species of $M_{\mathrm{r}} \sim 400,000, \sim 200,000$, and $\sim 38,000$ (dye front). In contrast to normal platelets, the platelets from the Bernard-Soulier patient show only a band that co-migrates with free thrombin.

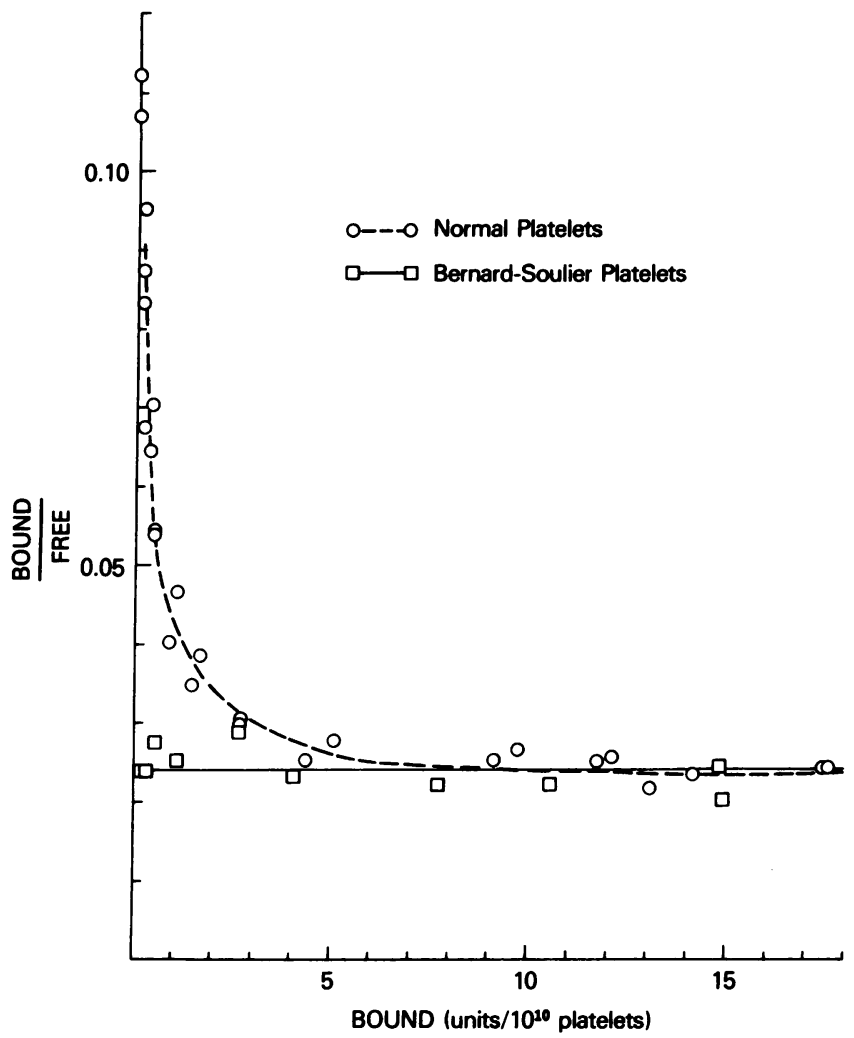

Figure 7. Scatchard plot representing the binding of thrombin to normal and Bernard-Soulier platelets. The horizontal line through the Bernard-Soulier points approximates the asymptote of the hyperbolic curve depicting the data for the normal platelets. The vertical intercept of this line (bound/free $\sim 2.3 \mathrm{ml} / 10^{10}$ cells) agrees well with the bound/free ratio measured in the presence of hirudin $(2.6 \pm 0.40 \mathrm{ml}$ / $10^{10}$ cells, mean $\pm \mathrm{SD}$ ). The binding experiments were performed at $25^{\circ} \mathrm{C}$.

\section{Discussion}

We have studied the binding of alpha thrombin to the platelet surface by cross-linking radiolabeled thrombin to platelets with the bifunctional agents DSP and DSS and by measuring the

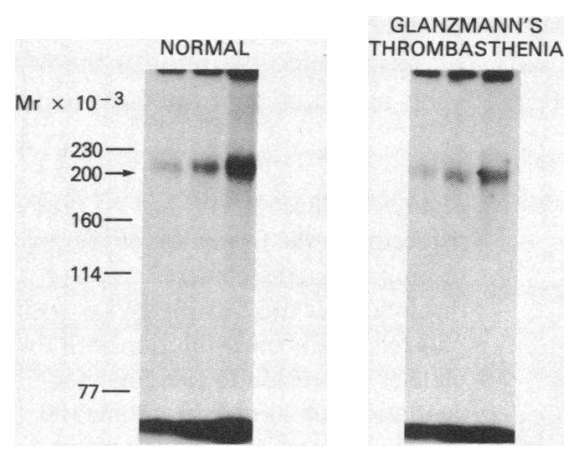

Figure 8. Autoradiograph of normal platelets and platelets from a patient with Glanzmann's thrombasthenia, exposed to (left to right) 10, 20 , and $100 \mathrm{nM}^{125} \mathrm{I}$-thrombin and cross-linked with $1 \mathrm{mM}$ DSS. The samples were unreduced. The migration distance corresponding to $M_{\mathrm{r}}$ $\sim 200,000$ is indicated by an arrow. ${ }^{125}$ I-thrombin cross-linked complexes of the thrombasthenic patient's platelets are indistinguishable from those formed with normal platelets. Molecular weight standards were the same as shown in Fig. 1. 


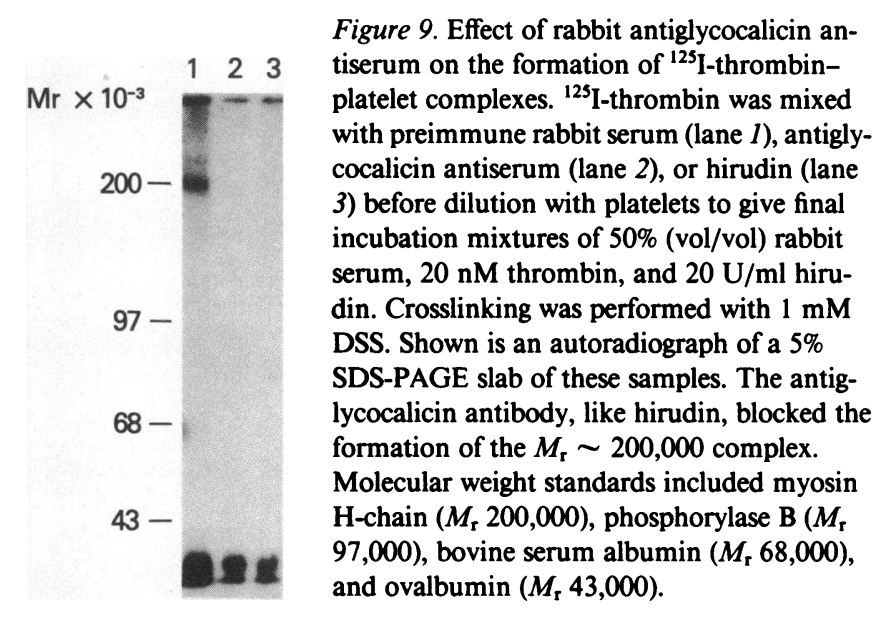

association of thrombin with platelets under equilibrium conditions. As we and others have shown, in the presence of the leech peptide hirudin, the only thrombin binding that occurs is unsaturable, and is equivalent to the nonspecific binding calculated from the limiting value of bound/free on a Scatchard plot (Fig. 7) $(19,20)$. When hirudin was added to ${ }^{125}$ I-thrombin before mixing with platelets and exposure to a cross-linking agent, the only autoradiographic bands appearing after electrophoretic separation (SDS-PAGE) were very faint, at the top of the gels (to be discussed below) and at $M_{\mathrm{r}} \sim 38,000$, corresponding to a small amount of free thrombin (Figs. 1 and 9). Therefore, the ${ }^{125}$ I bands we observed on SDS-PAGE of samples prepared without hirudin are interpreted to have resulted from the reaction of thrombin with a specific membrane binding site.

When normal platelets were cross-linked to ${ }^{125}$ I-thrombin in the absence of hirudin, a consistent finding was a species with $M_{\mathrm{r}} \sim 200,000$, compatible in size with a bimolecular complex of one thrombin $\left(M_{\mathrm{r}} \sim 38,000\right)$ and one GPIb $\left(M_{\mathrm{r}} \sim 165,000\right)$. In 5\% gels, ${ }^{125}$ I-bands were also detected at the dye front and at the origin $\left(M_{\mathrm{r}}>350,000\right)$. The possibility of complexes of $M_{\mathrm{r}}$ lower than 200,000 was excluded by $10 \%$ SDS-PAGE, in which the only bands visualized were at the top of the gel and at $M_{\mathrm{r}}$ $\sim 38,000$ (uncross-linked thrombin).

In gels of $0.5 \%$ agarose and $2.25 \%$ acrylamide, a minor crosslinked species of $M_{\mathrm{r}} \sim 400,000$ was also evident (Fig. 3). Although it was not always well separated from the band at $M_{\mathrm{r}}$ $\sim 200,000$, the absence of any radiolabeled material in the $M_{\mathrm{r}}$ range $200,000-350,000$ in $5 \%$ gels indicated that the faint band

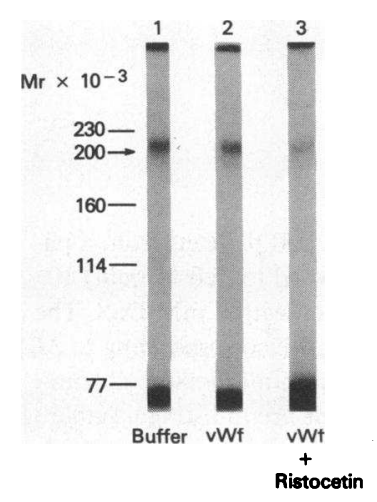

Figure 10. Effect of vWf or vWf plus ristocetin on the formation of ${ }^{125} \mathrm{I}$ thrombin-platelet complexes. ${ }^{125} \mathrm{I}$ thrombin was mixed with vWf or vWf plus ristocetin before dilution with the platelet suspension to give final concentrations of $20 \mathrm{nM}$ thrombin, 100 $\mu \mathrm{g} / \mathrm{ml} \mathrm{vWf}$, and $1 \mathrm{mg} / \mathrm{ml}$ ristocetin. The apparent reduction in the autoradiographic intensity of the $M_{\mathrm{r}}$ $\sim 200,000$ formed in the presence of vWf plus ristocetin was confirmed by slicing the lanes and measuring the $\mathrm{cpm} / 2 \mathrm{~mm}$. By this method the $\sim 200,000-M_{\mathrm{r}}$ band in the vWf-ristoRistocetin cetin lane was reduced by $22 \%$.

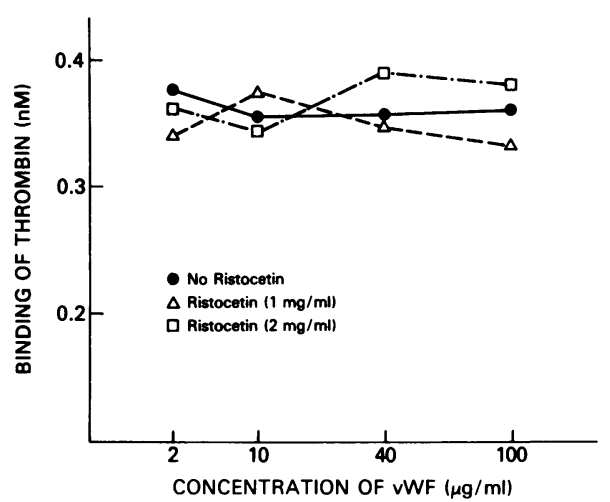

Figure 11. Effect of $\mathrm{vWf}$ and ristocetin on the binding of ${ }^{125} \mathrm{I}$-thrombin to platelets. Various concentrations of $\mathrm{vWf}(2-10 \mu \mathrm{g} / \mathrm{ml})$ were incubated with the platelets with or without ristocetin at room temperature for $15 \mathrm{~min}$ before the addition of $20 \mathrm{nM}^{125} \mathrm{I}$-thrombin. Specific binding of ${ }^{125} \mathrm{I}$-thrombin was measured as described in the text: (๑), without ristocetin; $(\Delta)$, in the presence of $1 \mathrm{mg} / \mathrm{ml}$ of ristocetin; ( $\square$ ), in the presence of $2 \mathrm{mg} / \mathrm{ml}$ of ristocetin. Purified $\mathrm{vWf}$ in the presence or absence of ristocetin had no effect on the binding of thrombin to platelets.

in the more porous system represented a distinct molecular complex rather than a group of complexes of $M_{\mathrm{r}} 200,000$ 400,000 . Since there are no recognized membrane proteins sufficiently large to produce a bimolecular unit of this size with thrombin, the $M_{\mathrm{r}} \sim 400,000$ band must be either $(a)$ a dimer of the $\sim 200,000-M_{\mathrm{r}}$ complex, $(b)$ a heteromultimer of the $\sim 200,000-M_{\mathrm{r}}$ complex and $\sim 5$ additional ${ }^{125}$ I-thrombin molecules, or $(c)$ multiple ${ }^{125}$ I-thrombin molecules linked to a membrane protein or group of proteins other than that in the $\sim 200,000-M_{\mathrm{r}}$ band. The latter two possibilities are unlikely both because they would require multiple cross-linking reactions within a single structure and because there is no evidence of the expected family of less cross-linked components of such a conglomerate. Therefore, the most reasonable explanation for the $\sim 400,000-M_{\mathrm{r}}$ complex is that it is a dimer of the $\sim 200,000-M_{\mathrm{r}}$ species. This implies that the thrombin-receptor units in the intact platelet membrane are in close proximity, since the bridging distance of DSP is only $12 \mathrm{~A}$. This possibility has previously been raised by Ganguly and Gould (21), who suggested that thrombin stimulation may lead to clustering of the thrombin receptors.

In addition to the cross-linked complexes with $M_{\mathrm{r}} \sim 200,000$ and $\sim 400,000$, most of the polyacrylamide gels retained a variable amount of material at the origin of the lanes, regardless of the porosity of the slab matrix. Although the $\sim 400,000-M_{\mathrm{r}}$ complex would not be expected to enter the $5 \%$ gels, the material remaining at the top of these slabs was frequently too concentrated to be explained by this complex alone. Furthermore, small amounts of material remained at the origin of the $0.5 \%$ agarose, $2.25 \%$ acrylamide slabs. Even hirudin, which prevented the formation of cross-linked complexes, did not always eliminate retention of radioactivity at the top of the electrophoretic lanes. Similar observations have been commonly made by others using cross-linking agents $(16,17,22)$. The phenomenon is generally attributed to entrapment of radiolabeled protein in an extensively cross-linked matrix of high molecular weight and limited solubility in SDS. This explanation is consistent with our observation that only $38 \%$ of the radioactivity of a thrombin-platelet sample 
remained in the supernatant after solubilization with SDS if cross-linking was accomplished with $10 \mathrm{mM}$ DSP, whereas $90 \%$ remained in the supernatant if the DSP was only $1 \mathrm{mM}$. Also, when platelet proteins (unexposed to thrombin) were separated on SDS-PAGE and stained with Coomassie Blue, previous treatment of the sample with cross-linking agents was associated with marked retention of material at the electrophoretic origin, consistent with a highly cross-linked matrix of platelet protein unrelated to thrombin. Therefore, we feel that the radioactivity remaining at the origin of the electrophoretic separations of the ${ }^{125}$ I-thrombin-platelet samples includes nonspecifically trapped material and not covalently bound thrombin-platelet complexes of $M_{\mathrm{r}}>400,000$.

Our observations, therefore, favor a single binding site for thrombin to the platelet membrane, although equilibrium studies have previously demonstrated two classes of receptors and the curvilinear configuration of our own Scatchard analysis of normal thrombin binding is consistent with this interpretation (Fig. 7). The possibility that we have selectively lost a class of crosslinked complexes during our sample preparation for SDS-PAGE appears unlikely, since $\sim 90 \%$ of the ${ }^{125}$ I-thrombin originally bound to the platelets was solubilized in SDS for electrophoresis. Furthermore, the results of the equilibrium studies are as compatible with a single binding site that manifests negative cooperativity as they are with the presence of two independent binding sites.

Most of our experiments were performed with a thrombin concentration ( $20 \mathrm{nM})$, which should have been sufficient to saturate the high affinity receptor class $\left(K_{d} 0.2 \mathrm{nM}\right)$ and to bind extensively to the low affinity class $\left(K_{d} 30 \mathrm{nM}\right)$. To evaluate whether the minor $\sim 400,000-M_{\mathrm{r}}$ complex identified under these conditions might represent the low capacity, high affinity binding site, studies were repeated with thrombin concentrations as low as $0.1 \mathrm{nM}$, which should have highlighted binding to the high affinity receptor. However, the $\sim 200,000-M_{\mathrm{r}}$ complex remained dominant, approximately sevenfold as intense as the $\sim 400,000$ $M_{\mathrm{r}}$ complex, just as when the much higher thrombin concentrations were used. This is further evidence, therefore, that thrombin binds to the same site regardless of the concentration of thrombin in solution.

Although this conclusion agrees with the work of Tollefsen and Majerus (22), who found a single complex of $M_{\mathrm{r}} \sim 200,000$ when crosslinking DFP-thrombin to platelets with glutaraldehyde, it is not supported by the results of Larsen and Simons (23), who used a photo-activatable thrombin analogue. When this analogue was blocked at its active site, it formed cross-linked complexes of $M_{\mathrm{r}} \sim 400,000, \sim 200,000$, and $\sim 46,000$ with platelets at thrombin concentrations $>20 \mathrm{nM}$, whereas only the $\sim 200,000-M_{\mathrm{r}}$ complex was apparent at thrombin concentrations $\leq 2 \mathrm{nM}$. When the active site of the analogue was not blocked, the $M_{\mathrm{r}}$ of the 200,000 complex shifted to $\sim 120,000$. The differences between these observations and ours may be related to the fact that in the earlier studies thrombin binding occurred with the platelets suspended in a modified Tyrode's buffer without protease inhibitors. This may have allowed proteolysis of the platelet membrane or the thrombin-receptor complexes. Proteolysis appeared to be prevented in our study by the presence of EDTA or EDTA with leupeptin and NEM. Coller has shown that GPIb is susceptible to proteolysis, which can be inhibited by these agents (24). Harmon and Jamieson (25) have also recently published evidence for thrombin receptor heterogeneity, but their technique of radiation inactivation determines the size of functional units rather than the size of the specific protein to which thrombin binds.

Glanzmann's platelets, which lack GPIIb/IIIa, formed crosslinked complexes with ${ }^{125}$ I-thrombin indistinguishable from those seen with normal platelets (Fig. 8). GPIIb/IIIa, therefore, appears not to contain the thrombin binding site. This conclusion is consistent with the lack of binding inhibition in the presence of the monoclonal antibody 10E5. Furthermore, it agrees with the observations of White, Workman, and Lundblad (26), who demonstrated normal thrombin binding to Glanzmann's platelet under equilibrium conditions.

On the other hand, our studies with Bernard-Soulier platelets, which neither generated the cross-linked thrombin complexes nor demonstrated any specific thrombin binding at equilibrium, strongly suggest that thrombin binds to GPIb. Nevertheless, because Bernard-Soulier platelets are known to have membrane abnormalities in addition to their absence of GPIb, other lines of evidence are required to assign the binding site to this glycoprotein (7). Such evidence is provided by the marked inhibition of thrombin binding in the presence of the polyclonal antiglycocalicin antiserum. By equilibrium binding methods, this antiserum eliminated $\sim 80 \%$ of specific thrombin binding, and by the cross-linking technique the antiserum prevented formation of the $\sim 200,000-M_{\mathrm{r}}$ complex. These studies, therefore, localize the binding site to a particular domain of GPIb, the glycocalicin portion of the molecule. This localization is also supported by the behavior of the $\sim 200,000-M_{\mathrm{r}}$ complex under reducing conditions (Fig. 2). In the presence of DTT the $M_{\mathrm{r}}$ of the complex, formed with the noncleavable cross-linking agent, decreased by $\sim 20,000$, consistent with the loss expected by reductive cleavage of the beta (nonglycocalicin) portion of GPIb $\left(M_{\mathrm{r}} 23,000\right)$ and the A chain of thrombin $\left(M_{\mathrm{r}} \sim 4,600\right)(27,28)$. Furthermore, this behavior of the reduced complex implies that the crosslinking is to the $\mathrm{B}$ chain of the thrombin molecule.

In an attempt to localize the thrombin binding site even more precisely, the cross-linking studies were performed in the presence of the monoclonal antibody $6 \mathrm{DI}$, which inhibits the ristocetin-dependent binding of vWf to GPIb (14). This antibody had no apparent effect on formation of the $\sim 200,000-M_{\mathrm{r}}$ complex. Therefore, similar studies were performed to see whether vWf itself would inhibit thrombin binding in the presence of ristocetin. Although the cross-linking studies suggested that the vWf multimers, which are manyfold larger than the 6D1 antibody, might have a moderate inhibitory effect on thrombin binding ( $\sim 20 \%)$, this impression was not confirmed by equilibrium binding methods. Kao et al. (29) found a similar lack of competition of $\mathrm{vWf}$ and thrombin for platelet binding. Therefore, it appears that thrombin binds at a site beyond the realm where steric hindrance from the very large vWf is operative.

In summary, our data are consistent with the conclusion that platelets bind thrombin specifically to a single species of membrane protein, GPIb, despite evidence from equilibrium studies that two functional classes of binding sites exist. Furthermore, this binding occurs between the B chain of the thrombin molecule and the glycocalicin portion of GPIb, at a point remote from where $v W f$ binds in the presence of ristocetin.

\section{References}

1. Fenton, J. W. II. 1981. Thrombin specificity. Ann. NY Acad. Sci. 370:468-495.

2. Tollefsen, D. M., J. R. Feagler, and P. W. Majerus. 1974. The 
binding of thrombin to the surface of human platelets. J. Biol. Chem. 249:2646-2651.

3. Ganguly, P., and N. L. Gould. 1979. Thrombin receptors of human platelets: thrombin binding and antithrombin properties of glycoprotein I. Br. J. Haematol. 42:137-145.

4. Okumura, T., M. Hasitz, and G. A. Jamieson. 1978. Platelet glycocalicin. J. Biol. Chem. 253:3435-3443.

5. Nachman, R. L., E. A. Jaffe, and B. B. Weksler. 1977. Immunoinhibition of ristocetin-induced platelet aggregation. J. Clin. Invest. 59:143-148.

6. Jamieson, G. A., and T. Okumura. 1978. Reduced thrombin binding and aggregation in Bernard-Soulier platelets. J. Clin. Invest. 61:861-864.

7. Clemetson, K. J., J. L. McGregor, J. E. Dechavanne, and E. F. Luscher. 1982. Characterization of the platelet membrane glycoprotein abnormalities in Bernard-Soulier syndrome and comparison with normal by surface-labeling techniques and high-resolution two-dimensional gel electrophoresis. J. Clin. Invest. 70:304-311.

8. Degos, L., A. Dautigny, J. C. Brouet, M. Colombani, N. Ardaillou, J. P. Caen, and J. Colombani. 1975. A molecular defect in thrombasthenic platelets. J. Clin. Invest. 56:236-240.

9. Corash, L., H. Tan, and H. R. Gralnick. 1977. Heterogeneity of whole blood platelet populations. I. Relationship between buoyant density, cell volume, and ultrastructure. Blood. 49:71-87.

10. David, G. S., and R. A. Reisfeld. 1974. Protein iodination with solid state peroxidase. Biochemistry. 13:1014-1021.

11. Horne, M. K. III. 1985. The adsorption of thrombin to polypropylene tubes: the effect of polyethylene glycol and bovine serum albumin. Thromb. Res. 37:201-212.

12. Solum, N. O., I. Hagen, C. Fillion-Myklebust, and T. Staback. 1980. Platelet glycocalicin: its membrane association and solubilization in aqueous media. Biochim. Biophys. Acta. 597:235-246.

13. Gralnick, H. R., S. B. Williams, and B. S. Coller. 1985. Asialo von Willebrand factor interactions with platelets: interdependence of glycoproteins $\mathrm{Ib}$ and IIb/IIIa for binding and aggregation. J. Clin. Invest. 75:19-25.

14. Coller, B. S., E. I. Peerschke, L. E. Scudder, and C. A. Sullivan. 1983. Studies with a murine monoclonal antibody that abolishes ristocetin-induced binding of von Willebrand factor to platelets: additional evidence in support of GPIb as a platelet receptor for von Willebrand factor. Blood. 61:99-110.

15. Coller, B. S., E. I. Peerschke, L. E. Scudder, and C. A. Sullivan. 1983. A murine monoclonal antibody that completely blocks the binding of fibrinogen to platelets produces a thrombasthenic-like state in normal platelets and binds to glycoprotein IIb and/or IIIa. J. Clin. Invest. 72:325-338.
16. Glenn, K., D. F. Bowen-Pope, and R. Ross. 1982. Platelet-derived growth factor. III. Identification of a platelet-derived growth factor receptor by affinity labeling. J. Biol. Chem. 257:5172-5176.

17. Lomount, A. J., and G. Fairbanks. 1975. Chemical probes of extended biological structures: synthesis and properties of the cleavable protein crosslinking reagent $\left[{ }^{35} \mathrm{~S}\right]$ dithiobis (succiminidyl propionate). J. Mol. Biol. 104:243-261.

18. Laemmli, U. 1970. Cleavage of structural proteins during the assembly of the head of bacteriophage T4. Nature (Lond.). 227:680-685.

19. Ganguly, P., and W. J. Sonnichsen. 1976. Binding of thrombin to human platelets and its possible significance. Br. J. Haematol. 34:291-301.

20. Tam, S. W., J. W. Fenton, and T. C. Detwiler. 1979. Dissociation of thrombin from platelets by hirudin. J. Biol. Chem. 254:8723-8725.

21. Ganguly, P., and N. L. Gould. 1979. Receptor aggregation: a possible mechanism of platelet stimulation by thrombin. Thromb. Res. 15:879-884.

22. Tollefsen, D. M., and P W. Majerus. 1976. Evidence for a single class of thrombin-binding sites on human platelets. Biochemistry. 15:2144-2149.

23. Larsen, N. E., and E. R. Simons. 1981. Preparation and application of a photoreactive thrombin analogue: binding to human platelets. Biochemistry. 20:4141-4147.

24. Coller, B. S. 1982. Effects of tertiary amine local anesthetics on von Willebrand factor-dependent platelet function: alteration of membrane reactivity and degradation of GPIb by a calcium-dependent protease(s). Blood. 60:731-743.

25. Harmon, J. T., and G. A. Jamieson. 1985. Thrombin binds to a high-affinity $\sim 900,000$-dalton site on human platelets. Biochemistry. 24:58-64.

26. White, G. C., E. F. Workman, and R. L. Lundblad. 1978. Thrombin binding to thrombasthenic platelets. J. Lab. Clin. Med. 91:76-82.

27. Phillips, D. R., and P. P. Agin. 1977. Platelet plasma membrane glycoproteins: evidence for the presence of nonequivalent disulfide bonds using nonreduced-reduced, two-dimensional gel electrophoresis. J. Biol. Chem. 252:2121-2126.

28. Fenton, J. W. II, B. H. Landis, D. A. Walz, and J. S. Finlayson. 1977. Human thrombins. In Chemistry and Biology of Thrombin. R. L. Lundblad, J. W. Fenton II, and K. G. Mann, editors. Ann Arbor Science, Ann Arbor. 43-70.

29. Kao, K. J., S. V. Pizzo, and P. A. McKee. 1979. Demonstration and characterization of specific binding sites for Factor VIII/von Willebrand factor on human platelets. J. Clin. Invest. 63:656-664. 